OPEN ACCESS

Edited by:

Vincent Pialoux

Claude Bernard University Lyon 1 ,

France

Reviewed by:

Tadej Debevec,

Jožef Stefan Institute, Slovenia

Jian Cui,

Pennsylvania State University,

United States

*Correspondence:

Lee Taylor

lee.taylor@aspetar.com

Specialty section:

This article was submitted to

Exercise Physiology,

a section of the journal

Frontiers in Physiology

Received: 05 April 2017

Accepted: 18 July 2017

Published: 02 August 2017

Citation:

Barrington $\mathrm{JH}$, Chrismas BCR, Gibson OR, Tuttle J, Pegrum J, Govilkar S, Kabir C, Giannakakis N, Rayan F, Okasheh Z, Sanaullah A, Ng Man Sun S, Pearce O and Taylor L (2017) Hypoxic Air Inhalation and Ischemia Interventions Both Elicit

Preconditioning Which Attenuate Subsequent Cellular Stress In vivo Following Blood Flow Occlusion and

Reperfusion. Front. Physiol. 8:560. doi: 10.3389/fphys.2017.00560

\section{Hypoxic Air Inhalation and Ischemia Interventions Both Elicit Preconditioning Which Attenuate Subsequent Cellular Stress In vivo Following Blood Flow Occlusion and Reperfusion}

James H. Barrington ${ }^{1}$, Bryna C. R. Chrismas ${ }^{2}$, Oliver R. Gibson ${ }^{3}$, James Tuttle ${ }^{1}$, J. Pegrum ${ }^{4}$, S. Govilkar ${ }^{4}$, Chindu Kabir ${ }^{4}$, N. Giannakakis ${ }^{4}$, F. Rayan ${ }^{4}$, Z. Okasheh ${ }^{4}$, A. Sanaullah ${ }^{4}$, S Ng Man Sun ${ }^{4}$, Oliver Pearce ${ }^{4}$ and Lee Taylor ${ }^{5,6 *}$

1 Institute of Sport and Physical Activity Research, University of Bedfordshire, Luton, United Kingdom, ${ }^{2}$ Sport Science Program, College of Arts and Sciences, Qatar University, Doha, Qatar, ${ }^{3}$ Division of Sport, Health and Exercise Sciences, Department of Life Sciences, Centre for Human Performance, Exercise and Rehabilitation, Brunel University London, Uxbridge, United Kingdom, ${ }^{4}$ Milton Keynes University Hospital, Milton Keynes, United Kingdom, ${ }^{5}$ ASPETAR, Athlete Health and Performance Research Centre, Qatar Orthopedic and Sports Medicine Hospital, Doha, Qatar, ${ }^{6}$ School of Sport, Exercise and Health Sciences. Loughborough University, Loughborough, United Kingdom

Ischemic preconditioning (IPC) is valid technique which elicits reductions in femoral blood flow occlusion mediated reperfusion stress (oxidative stress, Hsp gene transcripts) within the systemic blood circulation and/or skeletal muscle. It is unknown whether systemic hypoxia, evoked by hypoxic preconditioning (HPC) has efficacy in priming the heat shock protein (Hsp) system thus reducing reperfusion stress following blood flow occlusion, in the same manner as IPC. The comparison between IPC and HPC being relevant as a preconditioning strategy prior to orthopedic surgery. In an independent group design, 18 healthy men were exposed to 40 min of (1) passive whole-body $\mathrm{HPC}\left(\mathrm{FiO}_{2}=0.143\right.$; no ischemia. $N=6)$, (2) IPC $\left(\mathrm{FiO}_{2}=0.209\right.$; four bouts of $5 \mathrm{~min}$ ischemia and $5 \mathrm{~min}$ reperfusion. $n=6)$, or (3) rest $\left(\mathrm{FiO}_{2}=0.209\right.$; no ischemia. $\left.n=6\right)$. The interventions were administered $1 \mathrm{~h}$ prior to $30 \mathrm{~min}$ of tourniquet derived femoral blood flow occlusion and were followed by $2 \mathrm{~h}$ subsequent reperfusion. Systemic blood samples were taken pre- and post-intervention. Systemic blood and gastrocnemius skeletal muscle samples were obtained pre-, 15 min post- (15PoT) and $120 \mathrm{~min}$ (120PoT) post-tourniquet deflation. To determine the cellular stress response gastrocnemius and leukocyte Hsp72 mRNA and Hsp32 mRNA gene transcripts were determined by RT-qPCR. The plasma oxidative stress response (protein carbonyl, reduced glutathione/oxidized glutathione ratio) was measured utilizing commercially available kits. In comparison to control, at 15PoT a significant difference in gastrocnemius Hsp72 mRNA was seen in HPC (-1.93fold; $p=0.007)$ and IPC (-1.97-fold; $p=0.006)$. No significant differences were observed in gastrocnemius Hsp32 and Hsp72 mRNA, leukocyte Hsp72 and Hsp32 mRNA, or oxidative stress markers $(p>0.05)$ between HPC and IPC. HPC provided 
near identical amelioration of blood flow occlusion mediated gastrocnemius stress response (Hsp72 mRNA), compared to an established IPC protocol. This was seen independent of changes in systemic oxidative stress, which likely explains the absence of change in Hsp32 mRNA transcripts within leukocytes and the gastrocnemius. Both the established IPC and novel HPC interventions facilitate a priming of the skeletal muscle, but not leukocyte, Hsp system prior to femoral blood flow occlusion. This response demonstrates a localized tissue specific adaptation which may ameliorate reperfusion stress.

Keywords: ischemia, oxidative stress, heat shock proteins, hypoxic preconditioning, ischemic preconditioning, knee surgery

\section{INTRODUCTION}

Tourniquets are used in several surgical procedures (Fitzgibbons et al., 2012). Relative to total knee replacement (TKR) surgery their use facilitates a near bloodless field, improving visualization of crucial structures, and accelerating the surgical procedure (Smith and Hing, 2010; Estebe et al., 2011). However, the benefits of tourniquet application are not without negative post-surgical side-effects e.g., delayed wound healing, vascular injury, muscular damage, and greater post-operative pain (Estebe et al., 2011; Fitzgibbons et al., 2012). Tourniquet mediated side-effects are not restricted to solely tissue damage (via direct tourniquet tissue compression), but also through ischemic reperfusion (IR) mediated metabolic disruption (Fitzgibbons et al., 2012). Reperfusion of occluded tissue (i.e., the leg after TKR specific tourniquet use) may lead to ischemic injury with activated leukocytes increasing reactive oxygen species (ROS) and/or free-radical formation, consequently resulting in transient elevations in oxidative stress (OS, Grace, 1994). Although ROS are essential for normal cellular signaling (Ray et al., 2012) and demonstrate an association with hormesis (Radak et al., 2008), a rapid increase in ROS can disrupt redox balance, resulting in OS induced protein denaturation and lipid oxidation (Halliwell and Chirico, 1993; Hawkins and Davies, 2001).

Reduced glutathione (GSH) is the most abundant endogenous antioxidant and can acquiesce increases in OS via its oxidation (e.g., cysteine originated reducing equivalent donation of $\mathrm{H}^{+}+$ $\mathrm{e}^{-}$to unstable molecules, such as, ROS; i.e., ROS scavenging) to oxidized glutathione (GSSG). The GSH:GSSG ratio can indicate cellular redox balance, with increases in the latter indicative of increased OS and a pro-oxidant state (Fisher-Wellman and Bloomer, 2009). During knee prosthesis implantation surgery, following $\sim 85$ min tourniquet application (thigh), both local (the occluded leg), and systemic (the arm) blood borne free radical

\footnotetext{
Abbreviations: CON, control experimental condition; HSP, heat shock protein; Hsp, heat shock protein gene transcript; HPC, hypoxic preconditioning; $\mathrm{HPC}_{\mathrm{I}}$, hypoxic preconditioning experimental condition; IPC, ischemic preconditioning; $\mathrm{IPC}_{\mathrm{I}}$, ischemic preconditioning experimental condition; IR, ischemic reperfusion; HReox, hypoxia/reoxygenation; RT-qPCR, one-step reverse transcription quantitative polymerase chain reaction; OS, oxidative stress; OS, oxidized glutathione; PC, protein carbonyl; ROS, reactive oxygen species; GSH, reduced glutathione; TKR, total knee replacement surgery.
}

generators hypoxanthine and xanthine oxidase increased, whilst GSH:GSSG only demonstrated significant pro-oxidant values locally, all of which were seen $5 \mathrm{~min}$ post-reperfusion (Karg et al., 1997). Elevated OS following IR of tissues is associated with inflammation and impaired wound healing (Soneja et al., 2005), and postulated to induce greater post-operative pain (Orban et al., 2006), whilst acquiescing OS reduces oxidant mediated apoptosis (Primeau et al., 2002) and post-operative pain (Waikakul et al., 1999). Interestingly, short non-lethal cycles of IR [ischemic preconditioning (IPC)] can prime the intended tissue and bestow protection for future IR stress (Murry et al., 1986; Saita et al., 2002). This method of IR has been shown to reduce knee surgery mediated increases in OS following tourniquet use when compared to controls (Koca et al., 2011). Furthermore, IPC in vivo has been shown as effective in reducing post-operative knee surgery pain and/or corresponding length of hospital stay (Memtsoudis et al., 2010).

Inhaled hypoxic air preconditioning (HPC) can infer cellular tolerance to subsequent hypoxia-mediated OS in vivo (Taylor et al., 2012), inducing similar protective effects to those conveyed by IPC (Bushell et al., 2002a,b; Berger et al., 2010; Samaja and Milano, 2015; Verges et al., 2015; Chacaroun et al., 2017), with the simplicity of the intervention (i.e., inhaling hypoxic air) advantageous compared to IPC. At present HPC, unlike IPC, has not been utilized prior to TKR to alleviate IR stress in vivo, despite similar protective effects. Characterization of occlusion mediated blood and muscle IR stress responses are heavily biased to OS markers. Given cells can initiate protective mechanisms during OS complimentary to GSH reduction, particularly increasing transcription and translation of a highly conserved cytoprotective family of proteins, known as heat shock proteins (HSPs) (Kalmar and Greensmith, 2009; Morton et al., 2009b), characterization of both OS and HSP responses to TKR like occlusion IR stress appears mechanistically warranted. Indeed, in vivo HPC mediated increases in basal HSP72 and hemeoxygenase-1 (HSP32) were both associated with resisting subsequent hypoxia/reoxygenation (HReox, Samaja and Milano, 2015) induced OS upon systemic HReox; attributed to restoring the function of OS mediated denatured proteins (principally HSP72, Taylor et al., 2010a, 2012) and degradation of ROSproducing heme molecules (principally HSP32, Gozzelino et al., 2010; Taylor et al., 2012). Readers are directed to multiple reviews 
for a detailed overview of the transcription factors and functional roles of HSP72 and HSP32 (Kregel, 2002; Morton et al., 2009b; Gozzelino et al., 2010; Henstridge et al., 2014).

Contextually, the cost of TKR surgery is $\sim \$ 7,500$ (Dakin et al., 2012), with the majority of this cost associated with long duration post-operative patient hospitalization (Smith et al., 2008). IPC has some efficacy for positively influencing variables associated with post-operative length of stay, however its administration typically occurs within the operating theater, and thus is not economically viable regarding time (theater availability is finite and often pressurized, operating list congestion, etc.). Therefore, a pre-operative (ideally on the ward) easily administrable preconditioning intervention (i.e., HPC) with positive physiological effects akin to IPC would be advantageous clinically (improved surgical outcome) and financially (reduced post-operative length of stay without increased time within theater). Logistically, HPC may be facilitated by supplementary low $\mathrm{O}_{2}$ gas inhalation in an equivalent manner to that of supplementary $\mathrm{O}_{2}$ or medical Nitrous oxide (Berkowitz et al., 1976; Greif et al., 2000), or via inhalation of nitrogen rich gas administered through small portable generators utilized in athletic training (Millet et al., 2010) or by creating rooms of low $\mathrm{O}_{2}$ concentration via nitrogen gas (Mekjavic et al., 2016; Simpson et al., 2016). Given acute exercise elicits significant OS across populations and modalities (Fatouros et al., 2004; Vincent et al., 2005; Hillman et al., 2011; Taylor et al., 2016), with this increase impacting muscle force production (Powers and Jackson, 2008), the benefits of HPC and IPC as a preconditioning strategies to ameliorate the cellular disruptions to contractile function in this paradigm also warrant further investigation. Physical activity (Debevec et al., 2017) and exercise training reduce OS (Miyazaki et al., 2001; Vinetti et al., 2015), with training induced elevations in intramuscular HSP content (Liu et al., 1999; Morton et al., 2009a) a potential pathway for these benefits (Oksala et al., 2014). As such HPC (and IPC) may provide an alternative strategy for individuals undertaking exercise for health, or athletic performance to reduce the potentially negative impact of acute OS (Braakhuis and Hopkins, 2015; Vinetti et al., 2015).

Therefore, the aim of this study was to examine the effects of interventional HPC and IPC prior to subsequent TKR like tourniquet induced IR stress, in comparison to a control condition using an ecologically valid model. It is hypothesized that a bout of either HPC or IPC would prime the HSP system, providing resistance to the physiological stresses induced via tourniquet ischemia. Furthermore, tourniquet mediated stress would be monitored via associated redox markers (GSH/GSSG, protein oxidation) post-occlusion.

\section{METHODS}

\section{Ethical Approval}

The protocol was ethically approved by the University of Bedfordshire's Sport and Exercise Science Departmental Human Ethics Committee and all participants signed informed consent in accordance with the ethical standards outlined in the 1964 Declaration of Helsinki.

\section{Participants and General Experimental Controls}

Eighteen apparently healthy male participants (see Table $\mathbf{1}$ for participant characteristics) volunteered and were subsequently randomly allocated to either control $(\mathrm{CON})$, or an HPC intervention $\left(\mathrm{HPC}_{\mathrm{I}}\right)$ or an IPC intervention (IPCI). A standardized meal [cornflakes $(50 \mathrm{~g})$, milk $(250 \mathrm{~mL})$, and 1 1 of water], as employed by others (Foster et al., 2016), was utilized within the experimental design. Relative to HSP and OS outcome variables, their between- and within-subject variation is established at rest (Fisher-Wellman and Bloomer, 2009; Sandström et al., 2009; Taylor et al., 2010b) and in response to stressors (Hillman et al., 2011; Lee et al., 2014; Peart et al., 2015). Accordingly an array of robust and previously employed experimental controls were incorporated within the study design to control for the confounding influences on HSP and/or OS responses of smoking (Anbarasi et al., 2006), caffeine (Whitham et al., 2006), glutamine (Wischmeyer et al., 2001; Zuhl et al., 2015), alcohol (Wu and Cederbaum, 2003), dietary consumption (Kuennen et al., 2011; Marshall et al., 2017), fluid intake (attainment of euhydration; Logan-Sprenger et al., 2015), generic supplementation (Pingitore et al., 2015), prior exercise (Lee et al., 2014), previous environmental (hypoxia and heat) exposures (Gibson et al., 2015b; Lee et al., 2016), and diurnal variation in basal HSP (Taylor et al., 2010a,b, 2011, 2012; Hillman et al., 2011; Costa et al., 2012). Apparent compliance was confirmed in 100\% of participants and was monitored via a questionnaire prior to each experimental visit (e.g., CON, $\mathrm{HPC}_{\mathrm{I}}$, or $\mathrm{IPC}_{\mathrm{I}}$ ).

Tourniquet applications throughout all relevant experimental procedures were produced via a straight $10 \mathrm{~cm}$ wide tourniquet cuff (AET, Anetic Aid, Leeds, UK) positioned superiorly to cotton wool padding on the thigh of the right leg, with pressure maintained by means of an electronic tourniquet unit (AET, Anetic Aid, Leeds, UK). During TKR this tourniquet pressure facilitates a bloodless field while minimizing direct compression injury (Worland et al., 1997).

\section{Experimental Design}

Participants arrived to the laboratory at 08:30 in a fasted stated (from at least 00:00 to arrival) and consumed the standardized meal for breakfast (this meal was provided again at 13:30 for lunch) and had anthropometric data collected. Blood pressure was recorded at baseline using an aneroid sphygmomanometer. They then rested within the laboratory under standardized environmental conditions until 11:30. At 11:30 participants were positioned in an inclined supine position for the remainder of the experimental protocol. Subsequently, participants rested for $1 \mathrm{~h}$ (until 12:30) prior to their 40 min allocated preconditioning intervention $\left(\mathrm{HPC}_{\mathrm{I}}\right.$ or $\left.\mathrm{IPC}_{\mathrm{I}}\right)$, with $\mathrm{CON}$ receiving an extended rest period.

\section{$\mathrm{HPC}_{\text {I }}$}

$H P C_{\text {I }}$ participants inhaled $\sim 14.3 \% \mathrm{O}_{2}$ (simulated altitude of 2,980 $\mathrm{m}$ above sea level) for $40 \mathrm{~min}$ (from 12:30 until 13:10) in normobaric pressure via an adjustable hypoxicator (Everest Summit II, The Altitude Centre, UK) which produced the necessary hypoxic load via $\mathrm{O}_{2}$ filtration. Heart rate (HR; 
TABLE 1 | Participant characteristic data.

\begin{tabular}{|c|c|c|c|c|c|c|c|c|c|}
\hline \multirow[t]{2}{*}{ Measure } & \multicolumn{3}{|c|}{$\operatorname{coN}(n=6)$} & \multicolumn{3}{|c|}{$\mathrm{HPC}_{I}(n=6)$} & \multicolumn{3}{|c|}{$\mathrm{IPC}_{\mathrm{I}}(n=6)$} \\
\hline & Mean & $S D$ & Range & Mean & $S D$ & Range & Mean & $S D$ & Range \\
\hline Age (years) & 22.2 & 2.9 & $18-26$ & 20.8 & 2.4 & $19-25$ & $18.5^{\star}$ & 0.6 & $18-19$ \\
\hline Height (m) & 1.83 & 0.06 & $1.75-1.92$ & 1.77 & 0.10 & $1.67-1.93$ & 1.79 & 0.04 & $1.73-1.83$ \\
\hline Mass (kg) & 80.4 & 12.4 & $62.8-93.4$ & 73.5 & 8.7 & $61.9-86.6$ & 76.7 & 7.8 & $64.8-87.4$ \\
\hline Lean mass (\%) & 85.8 & 3.5 & $79.3-88.5$ & 84.9 & 5.3 & $78.9-91.4$ & 86.5 & 3.0 & $81.5-90.1$ \\
\hline Fat mass (\%) & 14.2 & 3.5 & $11.5-20.7$ & 15.3 & 5.5 & $8.6-22.1$ & 13.5 & 3.0 & $9.9-18.5$ \\
\hline Thigh circumference (cm) & 44.7 & 2.6 & $40-47$ & 42.8 & 2.1 & $40-46$ & 43.3 & 2.4 & $39-46$ \\
\hline Systolic blood pressure (mmHg) & 124.0 & 3.0 & $120-129$ & 125.8 & 1.9 & $123-129$ & 125.5 & 2.1 & $123-129$ \\
\hline Diastolic blood pressure (mmHg) & 76.2 & 7.0 & 65-83 & 75.0 & 6.0 & $65-81$ & 79.7 & 8.0 & 70-92 \\
\hline
\end{tabular}

* Significant difference vs. CON $(p<0.05)$.

b. $\left.\min ^{-1}\right)$ and peripheral oxyhaemoglobin saturation $\left(\mathrm{SpO}_{2} ; \%\right)$ were measured every 5 min via finger pulse oximetry (Onyx ${ }^{\circledR}$ II 9550, Nonin Medical, USA) throughout the $\mathrm{HPC}_{I}$ intervention.

\section{$\mathrm{IPC}_{\mathrm{I}}$}

$I P C_{\mathrm{I}}$ received four cycles of $5 \mathrm{~min}$ ischemia and $5 \mathrm{~min}$ reperfusion (total of $40 \mathrm{~min}$ from 12:30 until 13:10) at $100 \mathrm{mmHg}$ above the participant's systolic pressure on their right leg in line with previous research (Koca et al., 2011).

Upon cessation of the preconditioning intervention $\left(\mathrm{HPC}_{\mathrm{I}}\right.$ or $\mathrm{IPC}_{\mathrm{I}}$ ) or CON (13:10), participants rested again for $55 \mathrm{~min}$ (14:05) prior to their right leg being elevated at $45^{\circ}$ for $5 \mathrm{~min}$ (14:05-14:10), immediately followed by $30 \mathrm{~min}$ (14:10-14:40) tourniquet application, and subsequent $2 \mathrm{~h}(14: 40-16: 40)$ period of reperfusion (Figure 1).

Sample size calculations were determined via G.Power 3.1, (Universität Dusseldorf, Germany) (Faul et al., 2009) using data describing changes in Hsp72 mRNA from a publication external to our group (Mestre-Alfaro et al., 2012). For a two tailed test with an alpha of 0.05 and power of 0.80 , it was calculated that six participants were required to find an Hsp72 mRNA increase of 3.8 -fold significant. This sample size is $\geq$ others in the field (Puntschart et al., 1996; Febbraio and Koukoulas, 2000; Fehrenbach and Northoff, 2001; Fehrenbach et al., 2003b; Liu et al., 2004; Mee et al., 2016).

\section{Blood Sampling \\ Preparation for Initial Storage}

Venous blood was drawn from an antecubital vein into three separate $4 \mathrm{~mL}$ Vacuette tubes (Vacuette ${ }^{\circledR}$, Grenier Bio-One, UK) treated with either $\mathrm{K}_{3}$ EDTA (Hsp), sodium citrate (glutathione) or lithium heparin [protein carbonyl (PC)] with all tubes filled to capacity. Blood samples were obtained (see Figure 1) at basal and immediately post-intervention (PoI), whilst also immediately pre-tourniquet application (PrT), 15 min posttourniquet removal (15PoT), and $120 \mathrm{~min}$ post-tourniquet removal (120PoT) (Figure 1).

\section{Leukocyte isolation for HSP analysis}

Blood treated with $\mathrm{K}_{3}$ EDTA underwent leukocyte isolation utilizing a previously validated technique (Tuttle et al., 2015;
Gibson et al., 2015a,b; Mee et al., 2016). Briefly, $1 \mathrm{~mL}$ of $\mathrm{K}_{3}$ EDTA blood was added to 1:10 red blood lysis solution (Miltenyi Biotec, $\mathrm{UK}$ ) and allowed to incubate at room temperature for $15 \mathrm{~min}$, prior to isolation via centrifugation at $400 \times \mathrm{g}$ for $5 \mathrm{~min}$ at $4^{\circ} \mathrm{C}$. Supernatant was removed and the remaining pellet was washed twice in $2 \mathrm{~mL}$ of PBS solution (Fisher Scientific, UK) at $400 \times$ $\mathrm{g}$ for $5 \mathrm{~min}$ at $4^{\circ} \mathrm{C}$. The pellet was suspended in $1 \mathrm{~mL}$ of PBS and separated equally into two $1.5 \mathrm{~mL}$ RNase free microtubes (ThermoFisher Scientific, UK) then centrifuged at 17,000 $\times \mathrm{g}$ for $5 \mathrm{~min}$ at $4{ }^{\circ} \mathrm{C}$. The remaining supernatant was aspirated prior to the pellet being completely re-suspended in $200 \mu \mathrm{L}$ of TRIzol reagent (Sigma Aldrich, Dorset, UK) and stored at $-80^{\circ} \mathrm{C}$ for subsequent RNA extraction.

\section{Glutathione blood samples}

Two milliliters of sodium citrate treated blood was immediately added to $8 \mathrm{~mL}$ of freshly prepared 5\% metaphosphoric acid (Sigma Aldrich, Dorset, UK) and left to incubate on ice for 15 min prior to centrifugation at $12,000 \times \mathrm{g}$ for $15 \mathrm{~min}$ at $4^{\circ} \mathrm{C}$. The clarified supernatant was collected and stored at $-80^{\circ} \mathrm{C}$ until future analysis for total glutathione and GSSG utilizing commercially available kits [Glutathione (Total) Detection Kit, ADI-900-160, Enzo Life Sciences, Exeter, UK].

\section{Protein carbonyl blood samples}

A full $4 \mathrm{~mL}$ lithium heparinized blood tube was immediately centrifuged at $900 \times \mathrm{g}$ for $10 \mathrm{~min}$ at $4^{\circ} \mathrm{C}$ before the plasma was collected and stored at $-80^{\circ} \mathrm{C}$ for future determination of PC concentration utilizing commercially available kits (Protein Carbonyl Colorimetric Assay Kit, 10005020, Caymen Chemical Company, Michigan, USA).

\section{Blood Oxidative Stress Markers Whole-Blood Glutathione}

To determine the concentration of total glutathione, previously obtained supernatant $(50 \mu \mathrm{L})$ was diluted to 1:40 with assay buffer solution and transferred to a 96-well plate in accordance with the manufacturer's instructions. A standard curve was created through serially diluting $50 \mu \mathrm{L}$ GSSG standard and $50 \mu \mathrm{L}$ of assay buffer solution (100-12.5 pmol). A $150 \mu \mathrm{L}$ mixture of DTNB (5,5'-dithio-bis-2-nitrobenzoic acid) and 


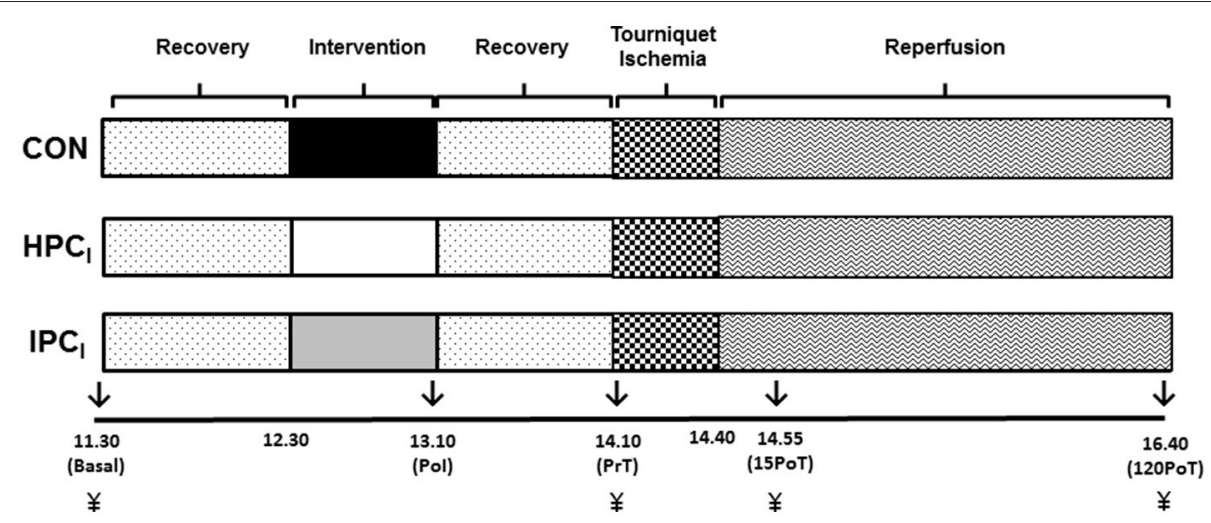

FIGURE 1 | Experimental overview blood samples $(\downarrow)$ were obtained at basal, immediately post-intervention (Pol), immediately pre-tourniquet application (PrT), 15 min post-tourniquet removal (15PoT), and 120 min post-tourniquet removal (120PoT) with gastrocnemius tissue ( $¥$ ) collected at PrT, 15PoT, and 120 PoT.

$10 \mu \mathrm{L}$ glutathione reductase was added to all wells to produce TNB (5-thio-2-nitrobenzoic acid) and immediately assessed via a microplate reader (Sunrise ${ }^{\mathrm{TM}}$, Tecan, Reading, UK) at an absorbance of $405 \mathrm{~nm}$ every minute for $10 \mathrm{~min}$. For determination of GSSG, the method outlined above was replicated with the addition of samples first being treated with $1 \mu \mathrm{L}$ of $2 \mathrm{M} 4$-Vinylpyridine (Sigma Aldrich, Dorset, UK) to block any free thiols from cycling the reaction. Four microliters of $2 \mathrm{M} 4$-Vinylpyridine was added to $200 \mu \mathrm{L}$ of GSSG standard to produce a standard curve. Samples and standards were incubated for $1 \mathrm{~h}$ and analyses were identical to the protocol for total glutathione. GSH was calculated via subtraction of GSSG concentrations from total glutathione and a final GSH/GSSG ratio was computed. All standards and samples were run in triplicate and an average was taken. The intra- and intercoefficient of variance for the assay kits were 3.4 and $3.6 \%$, respectively, in line with previous research (Taylor et al., 2012).

\section{Protein Carbonyl}

Plasma $(200 \mu \mathrm{L})$ was added to $800 \mu \mathrm{L}$ of $2,4-$ dinitrophenylhydrazine acting as the sample tube whilst $200 \mu \mathrm{L}$ of plasma was added to $800 \mu \mathrm{L}$ of $2.5 \mathrm{M}$ hydrochloric acid to serve as the control tube. All tubes were required to incubate in the dark for $1 \mathrm{~h}$ at room temperature with a brief vortex every $15 \mathrm{~min}$. One milliliter of $20 \%$ trichloroacetic acid was added to each tube, briefly vortexed and incubated on ice for 5 min prior to centrifugation at $10,000 \times \mathrm{g}$ for $10 \mathrm{~min}$ at $4^{\circ} \mathrm{C}$. This was followed by a $10 \%$ trichloroacetic acid wash, incubation on ice for $5 \mathrm{~min}$ and centrifuged at $10,000 \times \mathrm{g}$ for $10 \mathrm{~min}$ at $4^{\circ} \mathrm{C}$. Supernatant was discarded and the pellet suspended in a 1:1 ethanol/ethyl acetate wash before undergoing a thorough vortex and centrifugation at $10,000 \times \mathrm{g}$ for $10 \mathrm{~min}$ at $4{ }^{\circ} \mathrm{C}$. This was repeated twice more before the pellet was re-suspended in $500 \mu \mathrm{L}$ of guanidine hydrochloride and centrifuged at $10,000 \times \mathrm{g}$ for $10 \mathrm{~min}$ at $4^{\circ} \mathrm{C}$. An aliquot of $220 \mu \mathrm{L}$ of both sample and control was added to a 96-well plate and the absorbance was measured at $360 \mathrm{~nm}$ using a microplate reader (Sunrise ${ }^{\mathrm{TM}}$, Tecan, Reading, UK). Calculation of PC concentration was determined following the manufacturer's instructions. All samples and standards were analyzed in duplicate. The intra and inter-assay coefficient of variance are 4.7 and $8.5 \%$, respectively.

\section{Muscle Biopsies Muscle Biopsy Technique and Preparation for Initial Storage}

All biopsies were taken by medically qualified Orthopedic Surgeons, with full UK General Medical Council registration. Muscle biopsies were obtained using a previously validated and HSP specific in vivo technique (Morton et al., 2006, 2007, 2008, 2009a) applied to the lateral head of the gastrocnemius of the right leg. Biopsies were taken $3 \mathrm{~cm}$ apart in a proximal to distal fashion, along an anatomically located muscle mid belly plane under local anesthetic ( $2 \%$ lidocaine hydrochloride). The fascia of the muscle was specifically avoided (Trappe et al., 2013). Disposable manually primed biopsy needle guns were utilized (12 $\times 16$, Disposable Monopty Core Biopsy Instrument, Bard Biopsy Systems, USA). Samples collected (20-30 mg) were immediately frozen in liquid nitrogen $\left(-196^{\circ} \mathrm{C}\right)$ and stored at $-80^{\circ} \mathrm{C}$ for later analysis. Serial biopsies separated by $3 \mathrm{~cm}$ have been previously demonstrated not to provoke stress proteins in residual tissue (Khassaf et al., 2001). Muscle was obtained at PrT, 15PoT, and 120PoT (Figures 1, 3).

Muscle samples were later ground under liquid nitrogen to remove non-muscle (i.e., adipose, connective) tissue prior to homogenization with a sonicator (T10 Basic, IKA, ThermoFisher Scientific, Loughborough, UK) on ice in $1 \mathrm{~mL}$ TRIzol reagent, followed by a $10 \mathrm{~min}$ incubation period on ice, in preparation for RNA extraction.

\section{RNA Extraction Blood and Muscle Samples}

RNA was extracted utilizing a previously validated (Chomczynski and Sacchi, 1987) technique that has been utilized specifically for HSP assessment in vivo (Tuttle et al., 2015; Gibson et al., 2015a,b; Mee et al., 2016). Briefly, chloroform (Sigma Aldrich, Dorset, UK) was added to ( $200 \mu \mathrm{L}$ for muscle; $40 \mu \mathrm{L}$ for leukocytes) samples suspended in TRIzol reagent, then vortexed and left to incubate on ice for $10 \mathrm{~min}$ prior to centrifugation at $17,000 \times$ $g$ for $15 \mathrm{~min}$ at $4^{\circ} \mathrm{C}$. The aqueous phase was carefully aspirated 
and equal volume of ice-cold 2-propanol (Sigma Aldrich, Dorset, UK) was added before a $15 \mathrm{~min}$ incubation period on ice and subsequent centrifugation at $17,000 \times \mathrm{g}$ for $15 \mathrm{~min}$ at $4^{\circ} \mathrm{C}$. The supernatant was removed and the sample was washed with (1 $\mathrm{mL}$ for muscle; $100 \mu \mathrm{L}$ for blood) ice-cold $75 \%$ ethanol (Sigma Aldrich, Dorset, UK) ahead of centrifugation at $5,400 \times \mathrm{g}$ for $8 \mathrm{~min}$ at $4^{\circ} \mathrm{C}$. Two additional ethanol washes were performed. Remaining ethanol was aspirated and the pellet was allowed to air dry for $15 \mathrm{~min}$ prior to the addition of $50 \mu \mathrm{L}$ of RNA storage solution (Invitrogen, Paisley, UK). RNA quantity and quality were assessed optically at a density of $260 \mathrm{~nm}$ and ratios of $260 / 280$ and $260 / 230$, respectively, utilizing spectrophotometry (Nanodrop 2000c, ThermoFisher Scientific, Loughborough, UK). Only samples with a 260:280 ratio of between 1.9 and 2.15 were carried forward for reverse transcription and PCR amplification detailed below.

\section{One-Step Reverse Transcription Quantitative Polymerase Chain Reaction (RT-qPCR)}

Primers (Table 2) were designed using primer design software (Primer Quest and Oligoanalyzer-Integrated DNA technologies) and have been recently utilized elsewhere (Tuttle et al., 2015; Gibson et al., 2015a,b; Mee et al., 2016). During primer design, in line with (Tuttle et al., 2015), sequence homology searches were performed against the GenBank database to ensure the primers matched the gene of interest. Primers were designed to span exon-intron boundaries and avoided three or more guanine-cytosine bases within the last five bases at the 3' end of primer to avoid nonspecific binding. Further searches were performed to ensure primers did not contain secondary structures and intermolecular or intramolecular interactions (hairpins, self-dimer, and cross dimers), which can inhibit product amplification.

Relative Hsp mRNA expression was then quantified using RTqPCR adhering to the method adopted by Tuttle et al., (2015). Reactions $(20 \mu \mathrm{L})$ containing $10 \mu \mathrm{L}$ of SYBR Green RT-PCR Mastermix (Quantifast SYBR Green kit; Qiagen, Manchester, $\mathrm{UK}), 0.15 \mu \mathrm{L}$ of forward primer, $0.15 \mu \mathrm{L}$ of reverse primer, $0.2 \mu \mathrm{L}$ of reverse transcription mix (Quantifast RT Mix, Qiagen), and $9.5 \mu \mathrm{L}$ sample $(70 \mathrm{ng} \mathrm{RNA} / \mu \mathrm{L})$ were prepared using the Qiagility automated pipetting system (Qiagen). Each reaction was amplified in a thermal cycler (Rotorgene Q, Qiagen) and involved reverse transcription lasting $10 \mathrm{~min}$ at $50^{\circ} \mathrm{C}$ and a transcriptase inactivation and initial denaturation phase lasting $5 \mathrm{~min}$ at $95^{\circ} \mathrm{C}$. The PCR reaction then followed with a denaturation step lasting $10 \mathrm{~s}$ at $95^{\circ} \mathrm{C}$ and a primer annealing and extension stage lasting $30 \mathrm{~s}$ at $60^{\circ} \mathrm{C}$ repeated for 40 cycles. Fluorescence was measured following each cycle as a result of the incorporation of SYBR Green dye into the amplified PCR product. Melt curves (50$95^{\circ} \mathrm{C}$; Ramp protocol, 5-s stages) were analyzed for each reaction to ensure only the single gene of interest was amplified.

The relative quantification of mRNA expression for each sample was assessed by determining the ratio between the cycle threshold (CT)-value of the target mRNA and the CT-values for $\beta 2$-microglobulin. Fold change in relative mRNA expression was calculated using the 2- $\Delta \Delta \mathrm{CT}$ method (Schmittgen and Livak, 2008).

\section{Statistical Analyses}

All data was analyzed using the statistical software package IBM SPSS version 19.0 (SPSS Inc., Chicago IL, USA). Prior to any performance of inferential statistics, descriptive tables and graphical methods (Q-Q plots and scatter plots) were utilized to check for statistical assumptions with all data presented deemed to be normally distributed. A one-way ANOVA was used to assess for statistical differences between participants' anthropometric data. One-way repeated measures ANOVA was utilized to establish significant differences between hemoglobin saturation and HR during the hypoxic intervention period. Sphericity was assumed for all repeated measures analysis. Linear mixed models were used to identify significant group $\times$ time interactions in the remaining dependent variables across all groups. In the event of a significant $F$ ratio for both linear mixed models and one-way repeated measures ANOVA, the posthoc test Sidak was used to locate significant pairs. The most suitable covariant model was decided using the difference in -2 restricted log likelihood figures and the number of parameters of the two models tested against the $\chi^{2}$ critical statistic (Field, 2013). Furthermore, residuals were checked for normality and homogeneity of variance using Q-Q plots and scatter plots, respectively, and were considered plausible for all dependant variables. Statistical significance was assumed at $p<0.05$. Finally, Cohen's effect sizes for independent means were calculated utilizing the formula outlined by Cohen and were established as: small $(d=0.2)$, medium $(d=0.5)$, and large $(d=0.8)$ effects (Cohen, 1992).

\section{RESULTS}

A significant difference was observed in age $[F(2,15)=4.36, p=$ 0.032 ] between $\operatorname{IPC}_{I}$ and CON $(p=0.032)$. No other significant differences $(p \geq 0.34$ ) were noted in participant demographics (Table 1).

A significant main effect displayed a decrease in hemoglobin saturation $\left[F_{(8,40)}=17.331, p<0.001\right]$ between baseline and all subsequent time points $(p<0.05)$ in the $\mathrm{HPC}_{\mathrm{I}}$ intervention. However, there was no significant main effect $\left[F_{(8,40)}=1.130, p\right.$ $=0.365$ ] in HR noted by the same exposure (Figure 2).

Significant group $\times$ time interaction effects $(F=3.058, p=$ 0.048) were observed in muscle Hsp72 relative gene expression. There was an increase between time-points PrT and 15PoT (95\% CI $-3.771,-0.124 ; p=0.035)$ in CON displaying a large effect size (1.44). Also, between PrT and 120PoT, a pronounced $116 \%$ increase $(95 \% \mathrm{CI}-3.779,-0.400 ; p=0.014)$ was noted in $\mathrm{IPC}_{I}$ producing a large ES (1.59). Furthermore, when compared to $\mathrm{CON}$ at $15 \mathrm{PoT}$ muscle $\mathrm{Hsp} 72$ was lower in $\mathrm{HPC}_{I}(95 \%$ CI 0.634, 3.934; $p=0.007)$ and $\mathrm{IPC}_{I}$ (95\% CI 0.675, 4.114; $p=0.006$ ), both demonstrating large effect sizes (1.90 and 2.19, respectively) (Figure 3).

There were no significant $(p>0.05)$ group $\times$ time interaction effects for gastrocnemius Hsp32 $(F=0.147, p=0.961)$ (Figure 3) leukocyte Hsp72 $(F=1.195, p=0.347)$, leukocyte Hsp32 ( $F=$ $1.406, p=0.244)$, PC $(F=0.681, p=0.707)$, or GSH/GSSG $(F=$ $1.959, p=0.105)$ (see Table 3 ). 
TABLE 2 | Primer sequences used in One-step reverse transcription quantitative polymerase chain reaction.

\begin{tabular}{|c|c|c|c|c|}
\hline Target gene & Primer sequence $\left(5^{\prime}-3^{\prime}\right)$ & Reference sequence no. & Amplicon length (bp) & GC $\%$ content \\
\hline \multirow[t]{2}{*}{$\mathrm{B}_{2}$ microglobulin } & Forward: CCGTGTGAACCATGTGACT & NM_004048 & 19 & 52.63 \\
\hline & Reverse: TGCGGCATCTTCAAACCT & & 18 & 50.00 \\
\hline \multirow[t]{2}{*}{ HSP 72} & Forward: CGCAACGTGCTCATCTITGA & NM_005345 & 20 & 50.00 \\
\hline & Reverse: TCGCTTGTTCTGGCTGATGT & & 20 & 50.00 \\
\hline \multirow[t]{2}{*}{ HSP32 } & Forward: CAGCAACAAAGTGCAAGAT & NM_002133 & 19 & 42.11 \\
\hline & Reverse: CTGAGTGTAAGGACCCATC & & 19 & 52.63 \\
\hline
\end{tabular}

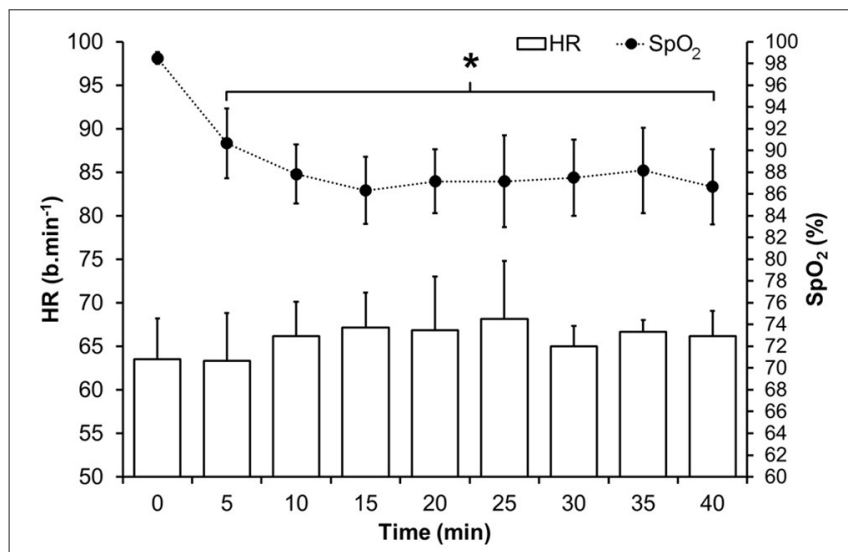

FIGURE 2 | Mean (SD) HR and oxyhaemoglobin saturation during the hypoxic intervention in $\mathrm{HPC}_{/}$. ${ }^{*}$ Indicates significant difference $(p<0.05)$ vs. baseline values.

\section{DISCUSSION}

In agreement with the presented hypothesis it is a novel experimental finding that both $\mathrm{IPC}_{\mathrm{I}}$ and $\mathrm{HPC}_{\mathrm{I}}$ primed the localized (gastrocnemius) HSP system producing a blunted response in Hsp72 mRNA post (15PoT) 30 min TKR like femoral blood flow occlusion (termed simply occlusion from this point forward) compared to CON (Figure 3). However, changes in local Hsp32 were not seen (Figure 3), contrary to the stated hypothesis, this lack of response may be indicative of minimal intramuscular OS within the gastrocnemius following $30 \mathrm{~min}$ of occlusion. This amelioration in Hsp72 response (15PoT) was seen without systemic changes in OS (PC and GSH:GSSG; Table 3) and leukocyte Hsp32, in agreement with the stated hypothesis.

HSPs are up-regulated in response to a variety of stressors relevant to IR and HReox mediated in vivo stress, including OS, hypoxia, and ischemia (Kalmar and Greensmith, 2009; Morton et al., 2009b; Gibson et al., 2017). Elevated localized Hsp72 mRNA in $\mathrm{CON}$ at $15 \mathrm{PoT}(+84 \pm 78 \%)$ indicates that the occlusion stressor was sufficient to potentiate initiation of the heat shock response (Theodorakis et al., 1999; Noble et al., 2008), whilst amelioration of this response (indicative of early phase IPC tissue protection; Bushell et al., 2002a,b; Loukogeorgakis et al., 2005) was seen when occlusion was preceded by $\operatorname{IPC}_{I}(+19 \pm$

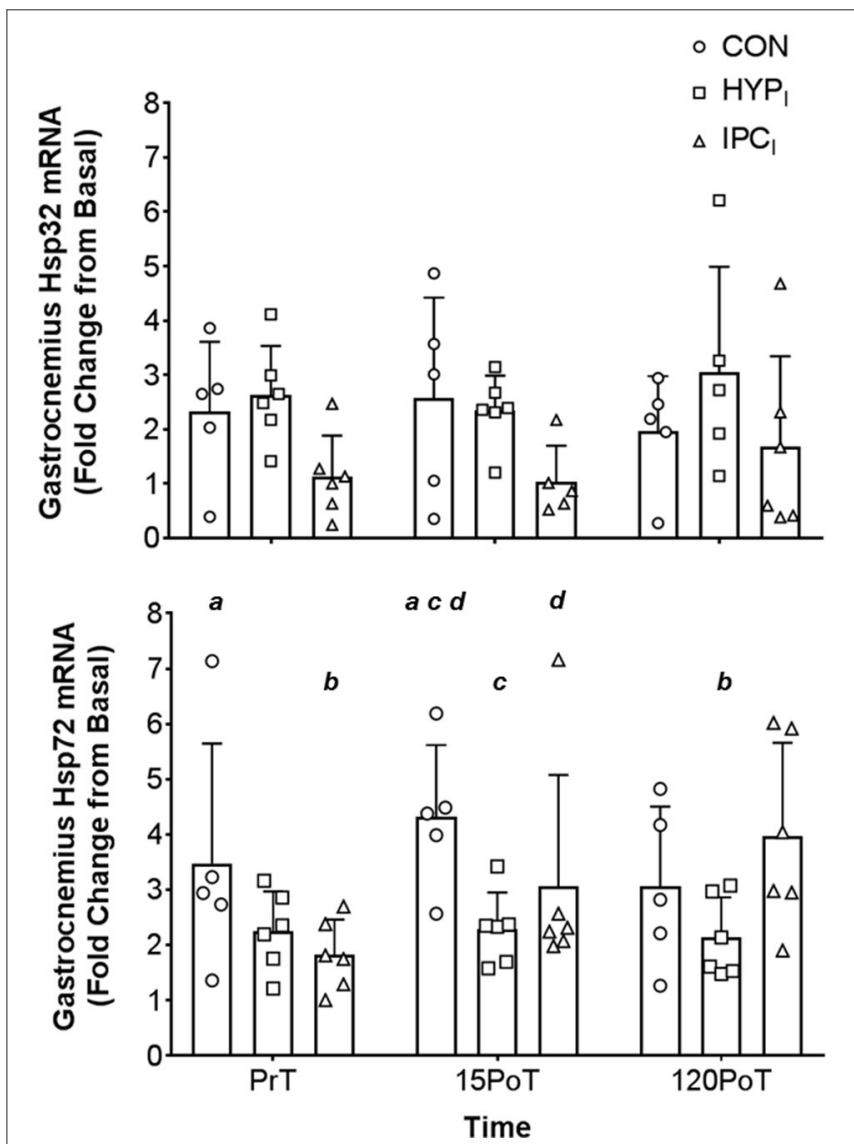

FIGURE 3 | Mean (SD) gastrocnemius Hsp32 mRNA (top) and Hsp72 mRNA (bottom) expression. Gastrocnemius samples were obtained from CON $(n=$ 5), $\mathrm{HPC}_{l}(n=6)$, and IPC $(n=6)$ immediately pre-tourniquet application ( $\left.\operatorname{PrT}\right)$, 15 min post-tourniquet removal (15PoT), and 120 min post-tourniquet removal (120PoT). All experimental samples were expressed relative to a laboratory control gastrocnemius sample (from Basal). Letters ( $a, b, c, d)$ denote significant differences between corresponding letter $(p<0.05)$.

$35 \%)$ or $\left(\mathrm{HPC}_{I}+7 \pm 33 \%\right.$; Figure 3). This change in Hsp72 mRNA within CON was not confounded by the larger basal gene expression of one participant in this group at this time point. Amelioration of Hsp72 mRNA is not novel regarding efficacy of IPC to blunt the respective gene response postreperfusion of occluded distal lower limb skeletal muscle (rat tibialis anterior) (Bushell et al., 2002a,b) however, blunting of 
the Hsp72 mRNA stress response in vivo via $\mathrm{HPC}_{I}$ within the presented paradigm is. It is ecologically relevant that the blunted response in $\mathrm{HPC}_{I}$ is contained within a time frame whereby surgery may be performed i.e., up to 120 PoTwith the time course of responses comparable to those observed in similar Hsp72 mRNA experiments (Febbraio et al., 2002; Tuttle et al., 2017). Mechanistically, this intervention mediated reduction in Hsp72 mRNA cannot be attributed to systemic reduction in OS (PC or GSH:GSSG; see Table 3) nor increased degradation of ROSproducing heme molecules by Hsp32 mRNA, as these outcome variables were unchanged within and between all conditions and time points (Table 3, Figure 3). However, the absence of localized measures of OS precludes inferences relative to a local to systemic difference in OS (although others have shown such a difference post knee surgery which utilized a tourniquet; Karg et al., 1997) mediating the local to systemic differential Hsp72 mRNA response at $15 \mathrm{PoT}$. Given the high affinity for changes in OS to induce a HSP32 and Hsp32 mRNA heat shock response (Gozzelino et al., 2010; Taylor et al., 2012), and the absence of changes in Hsp32 mRNA locally (and systemically), it is likely local Hsp72 mRNA amelioration via the interventions at 15PoT is mechanistically distinct from OS-at least within the occlusion paradigm utilized within the present design.

IPC has been cited to diminish circulatory redox disturbances associated with tourniquet-induced IR stress following TKR surgery (Koca et al., 2011). This is in disagreement with the current study, whereby it was noted that systemic OS markers remained unchanged within and between conditions at all times points when assessing lipid peroxidation (malondialdehyde concentrations) via measurement of thiobarbituric acid-reactive substances (Koca et al., 2011). This particular method of assessing malondialdehyde lacks specificity (Powers et al., 2010b), as such, the changes noted may be due to methodical inaccuracies rather than experimental effect. Additionally, systemic OS may not be a reliable surrogate marker for an intracellular response as aforementioned. It is however plausible that the 30 min occlusion utilized by the present study did not induce sufficient stress to observe changes in systemic OS markers and leukocyte Hsp mRNA (Table 3). This occlusion duration is lower than that commonly used during TKR surgery (mean $\pm S D$; $79.9 \pm$ $12.7 \mathrm{~min}$; Cheng et al., 2003). Therefore, it is expected that the OS would be greater during surgery thus the occlusion stressor in the present study is not completely externally valid. However, our pilot testing revealed a longer occlusion period was not tolerable in vivo by non-anesthetized humans thus precluding its implementation. In an exercise setting, variants of our IPC (de Groot et al., 2010; Bailey et al., 2012; Cruz et al., 2015; Kido et al., 2015; James et al., 2016; Sabino-Carvalho et al., 2016), and HPC (Lee et al., 2014; Turner et al., 2016; Chacaroun et al., 2017), have been implemented to induce positive physiological responses. These data reflecting positive responses in clinical paradigms (Landry et al., 1982; Tomai et al., 1999; Otani, 2008; Mateika et al., 2014; Verges et al., 2015; Baillieul et al., 2017). Our data present a novel contribution to the area demonstrating the potential facilitative role HSPs have in response to OS.

Early phase IPC protection is temporally aligned to a $1-2 \mathrm{~h}$ window (occlusion occurred within this window) post IPC, 
whilst late phase IPC protection commences $\sim 24 \mathrm{~h}$ post IPC and has a window of effect between $\sim 24$ and $\sim 72 \mathrm{~h}$ post IPC. This late phase protection is dependent on the induction of protective proteins (Loukogeorgakis et al., 2005) including HSP72 (Bushell et al., 2002a,b; Marber et al., 1993, 1995). HSP72 is thought to refold sub-lethally damaged proteins and diminish their interactions with viable proteins during repeated IR bouts (Marber et al., 1993), consequently conveying cellular protection. The cumulative IR signal in $\mathrm{IPC}_{I}$ [i.e., five distinct IR stressor bouts; intervention (four IR cycles) and occlusion (one $30 \mathrm{~min}$ IR cycle)] compared to $\mathrm{HPC}_{\mathrm{I}}$ [occlusion (one 30 min IR cycle) preceded by interventional HReox] is greater. Therefore, intervention activated IR preconditioning specific biological processes may have been exacerbated (particularly IR mediated cyclical increases in bradykinin and adenosine; Loukogeorgakis et al., 2005) by the subsequent occlusion IR stress and may underpin the enhanced gastrocnemius Hsp72 mRNA transcription seen at $120 \mathrm{PoT}$ in $\mathrm{IPC}_{\mathrm{I}}$, a response absent in $\mathrm{HPC}_{\mathrm{I}}$. This could be an early transcriptional level initiation of late phase IPC, within $\mathrm{HPC}_{\mathrm{I}}$, to which HSP72 protein translation is central (Loukogeorgakis et al., 2005). Therefore, this enhanced Hsp72 mRNA transcription at 120PoT could be interpreted as a priming mechanism for late phase IPC HSP72 translation within $\mathrm{IPC}_{\mathrm{I}}$, a response absent within HPC due to a lack of sufficient IR signal. In support of this postulation it has been eloquently shown elsewhere that remote limb IPC within humans results in cumulative up-regulation of peptides, with the magnitude of increase dependent on the number of discrete IR bouts (Hepponstall et al., 2012). Future research should examine the accumulative and temporally ordered effects (in line with recent attempts within a rat model; Kocman et al., 2015) of IPC (IR) and HPC (HReox) conveyed preconditioning in vivo within humans. A specific emphasis should be placed on adenosine, bradykinin, extracellular signaling proteins (ERK1/2, AKT; Winter et al., 2016) and relevant gene transcription and translation relative to the temporally ordered protective effects (i.e., early and late phase IPC tissue protection; Loukogeorgakis et al., 2005). The lack of such an approach is a limitation of the present study.

Prior research has shown that both acute hypoxic exposure (Taylor et al., 2010a) and IPC (Konstantinov et al., 2004) can stimulate leukocyte HSP72, which is in contrary to the data presented here (Table 3). Indeed in support of an association between OS and HSP responses antioxidant elevations are associated with leukocyte Hsp72 reductions (i.e., a lesser necessity for HSP72 transcription), thus OS necessitating HSP transcription could increase Hsp72 in leukocytes (Simar et al., 2012). Likewise antioxidant supplementation (500 IU.day ${ }^{-1}$ RRR-a-tocopherol for 8 days) attenuates the change in leukocyte Hsp72 mRNA after exhaustive exercise (Niess et al., 2002). The extended $75 \mathrm{~min}$ hypoxic exposure (approximately the same $14.3 \% \mathrm{O}_{2}$ as used within the present study) utilized previously (Taylor et al., 2010a), would have induced a more substantial OS stimulus for the induction of Hsp72, compared to the $40 \mathrm{~min}$ exposure utilized within $\mathrm{HPC}_{\mathrm{I}}$ in the present study. Given the very nature of IPC, and the lack of a change in circulating markers of OS, it is possible that the leukocytes were unable to experience the necessary fluctuations in OS that occurred locally within the skeletal muscle undergoing biopsy. As such it may be an experimental artifact associated with IPC alone that is responsible for the lack of Hsp72 mRNA responses in leukocytes rather than a mechanistic one. Utilizing a multi-gender sample and gene array analysis to assess Hsp72 (Konstantinov et al., 2004), with the former known to influence stress mediated changes in HSP (Paroo et al., 2002; Morton et al., 2009a) and the latter known to both over and underestimate gene transcript response (Feldman et al., 2002), may also explain some of the disparity in Hsp72 mRNA results.

Given that systemic OS was unchanged within and between all conditions (in line with previous data; Karg et al., 1997), it is likely that this absence of the potent OS stimuli (particularly ROS producing free-heme molecules) underpinned the lack of leukocyte Hsp32 mRNA response (Fehrenbach et al., 2003a) (Table 3). Although local OS markers were not obtained, absence of muscle Hsp32 mRNA change suggests only minimal (if any) disturbances in OS locally. To determine whether the $30 \mathrm{~min}$ occlusion was sufficiently stressful to induce intramuscular OS, future work should measure markers of this within the target tissue. To the authors' knowledge measurement of leukocyte and skeletal muscle Hsp32 mRNA within the presented in vivo occlusion paradigm is novel, with previous rodent model data lacking external validity to the presented TKR specific rationale (particularly time course). Rodent model data indicates that with five cycles of IPC (compared to the present study), muscle Hsp32 protein displays a 2 -fold increase with glutathione remaining unchanged, albeit only assessed $48 \mathrm{~h}$ post IPC (Badhwar et al., 2004). The stable Hsp32 mRNA-values could be a fiber type specific response, with type I muscle fibers shown to readily express HSP32 in comparison to a blunted response in type II fibers (Vesely et al., 1999). The lateral head of the gastrocnemius consists of equal proportions of both fiber types (Edgerton et al., 1975). Therefore, the response observed in the present study may only be proportional to the percentage of type II fibers in the biopsied muscle. A lack of fiber type characterization within the gastrocnemius samples within the present study is an experimental limitation that should be addressed by future research designs.

HPC has been shown to blunt IR mediated tissue damage in animal models (Beguin et al., 2005; Berger et al., 2010), however, to the author's knowledge, no previous studies have performed HPC in humans prior to limb-tourniquet application and subsequent IR stress. HPC is thought to confer cellular protection through similar mechanisms to IPC, essentially hormesis from appropriate protein accumulation (the precise mechanism/stimuli for such accumulation are not robustly described in vivo). The present data provides provisional evidence that in vivo HPC prior to IR stress provides similar reductions in localized cellular stress as an established IPC model. Interestingly, IPC has preliminary in vivo evidence supporting its use to reduce post-operative pain following TKR surgery (Memtsoudis et al., 2010), although some equivocal evidence is also present (Memtsoudis et al., 2014). Practically, IPC involves close monitoring to ensure correct ischemic periods (typically within theater), yet the $\mathrm{HPC}_{I}$ protocol used here would not require this human resource as the inhalation of hypoxia is 
continuous, thus potentially allowing HPC to take place during surgical preparation (perhaps on the ward utilizing methods described earlier). It should be noted that previous work has utilized intermittent hypoxia as a preconditioning strategy, future experimental designs should make comparisons between continuous and hypoxic interventions as previously utilized (albeit with differing clinical applications) in animals (Beguin et al., 2005) and humans (Lyamina et al., 2011; Chacaroun et al., 2017), to determine which elicits the most desirable preconditioning responses. From a practical perspective an intermittent approach may be less practical to administer in clinical setting if using the current equipment i.e., it would require manually switching between hypoxic and normoxic air. However, further experimentation is required to demonstrate whether localized reductions in cellular stress (Hsp72 mRNA) from $\mathrm{HPC}_{\mathrm{I}}$ (as also seen in $\mathrm{IPC}_{\mathrm{I}}$ ) can convey the same positive effects (reduced pain, accelerated wound healing, reduced length of hospital stay, as raised within the Introduction and Discussion sections) attributed to IPC, within externally valid models related to TKR like knee surgery which utilizes a tourniquet. Indeed, concerns could be raised to the safety of exposing elderly patients (population most likely to receive TKR surgery for example) to acute hypoxia. However, research has demonstrated that an elderly population with a high prevalence of cardiovascular disease tolerated hypobaric hypoxic remarkably well (Levine et al., 1997). Given that exercise and heating initiates increases in Hsp72 mRNA (Fehrenbach et al., 2001; Gibson et al., 2015a,b), in a temperature dependent manner (Gibson et al., 2016), passive heating [which has also been shown to increase Hsp72 mRNA; Horowitz et al., 1997; Maloyan et al., 1999] may also provide a viable preconditioning strategy that may be applied on the ward prior to surgery. In addition to the application presented (i.e., reperfusion) both HPC and IPC appear to initiate cellular responses (HSP increases) which are likely beneficial in across stimuli e.g., exercise, hypoxia, heat, though this is yet to be experimentally elucidated.

Although adequately powered it is important that the present data and postulations relative to the use of HPC are viewed relative to this sample size and preliminary nature of the experimental findings/design. It has been previously observed there can be high variability between participants with regards to basal and stress-mediated values of these measures, this variation based upon individual differences in physiological profile (Fehrenbach et al., 2000a,b, 2003a; Bruce et al., 2003) which require consideration relative to the presented data and discussion of the application of HPC vs. IPC prior to surgery. These reasons may explain the high basal Hsp72

\section{REFERENCES}

Anbarasi, K., Kathirvel, G., Vani, G., Jayaraman, G., and Shyamala Devi, C. S. (2006). Cigarette smoking induces heat shock protein 70 $\mathrm{kDa}$ expression and apoptosis in rat brain: modulation by bacoside A. Neuroscience 138, 1127-1135. doi: 10.1016/j.neuroscience.2005. 11.029
mRNA content in one CON group participant in the present study. As such further work with populations displaying more diverse phenotypes are warranted. In additions to experimental limitations acknowledged throughout the discussion, given many antioxidants are procured naturally from the diet, all with varying half-lives, this could have influenced OS related outcome variables within the present study (Powers et al., 2010a). Although every effort was made to control this (standardized morning and afternoon meal), it is extremely challenging to control participants' diet over a long period of time, while ensuring continued participation. Therefore, the lack of change in OS markers could have partly been due to dietary variation.

In summary, it can be seen that a bout of $\mathrm{HPC}_{\mathrm{I}}$ primed the HSP system thus bestowing localized cellular protection to tourniquet IR mediated stress induced via an ecologically valid TKR model. Furthermore, $\mathrm{HPC}_{\mathrm{I}}$ provided similar levels of cellular protection to $I_{P C}$, thus providing a novel framework for the use of $\mathrm{HPC}_{\mathrm{I}}$ to convey cellular protection in light of a subsequent IR related stressor.

\section{AUTHOR CONTRIBUTIONS}

JB participated in the study conception, methodological optimization, data collection, sample and statistical analysis and manuscript drafting and revisions. OG participated in the statistical analysis and manuscript drafting and revisions. JT aided in data collection, sample and statistical analysis and manuscript revision. $\mathrm{BC}$ assisted with statistical analysis and manuscript revision. OP, JP, SG, CK, NG, FR, ZO, AS, and SN contributed to the study conception and optimization of muscle sample collection. LT participated in study conception, optimization of muscle sample collection, manuscript drafting and revision. All authors have read and approved the final manuscript.

\section{AVAILABILITY OF DATA AND MATERIALS}

The datasets during and/or analyzed during the current study available from the corresponding author on reasonable request.

\section{ACKNOWLEDGMENTS}

The authors are extremely grateful for the technical assistance provided by Warwick Riley and Roisin McBride. Finally, the authors would like to thank all the individuals who participated in this study for their time and commitment. 
Baillieul, S., Chacaroun, S., Doutreleau, S., Detante, O., Pépin, J., and Verges, S. (2017). Hypoxic conditioning and the central nervous system: a new therapeutic opportunity for brain and spinal cord injuries? Exp. Biol. Med. 242, 1198-1206. doi: 10.1177/1535370217712691

Beguin, P. C., Joyeux-Faure, M., Godin-Ribuot, D., Lévy, P., and Ribuot, C. (2005). Acute intermittent hypoxia improves rat myocardium tolerance to ischemia. J. Appl. Physiol. 99, 1064-1069. doi: 10.1152/japplphysiol.00056.2005

Berger, M. M., Huhn, R., Oei, G. T., Heinen, A., Winzer, A., Bauer, I., et al. (2010). Hypoxia induces late preconditioning in the rat heart in vivo. Anesthesiology 113, 1351-1360. doi: 10.1097/ALN.0b013e3181 fce7ea

Berkowitz, B. A., Ngai, S. H., and Finck, A. D. (1976). Nitrous oxide \&quot;analgesia\&quot;: resemblance to opiate action. Science 194, 967-968. doi: $10.1126 /$ science. 982058

Braakhuis, A. J., and Hopkins, W. G. (2015). Impact of dietary antioxidants on sport performance: a review. Sports Med. 45, 939-955. doi: 10.1007/s40279-015-0323-x

Bruce, C. R., Carey, A. L., Hawley, J. A., and Febbraio, M. A. (2003). Intramuscular heat shock protein 72 and heme oxygenase-1 mRNA are reduced in patients with type 2 diabetes: evidence that insulin resistance is associated with a disturbed antioxidant defense mechanism. Diabetes 52, 2338-2345. doi: 10.2337 /diabetes.52.9.2338

Bushell, A. J., Klenerman, L., Davies, H., Grierson, I., McArdle, A., and Jackson, M. J. (2002a). Ischaemic preconditioning of skeletal muscle 2. Investigation of the potential mechanisms involved. J. Bone Joint Surg. Br. 84, 1189-1193. doi: 10.1302/0301-620X.84B8.9362

Bushell, A. J., Klenerman, L., Taylor, S., Davies, H., Grierson, I., Helliwell, T. R., et al. (2002b). Ischaemic preconditioning of skeletal muscle. 1. Protection against the structural changes induced by ischaemia/reperfusion injury. J. Bone Joint Surg. Br. 84, 1184-1188. doi: 10.1302/0301-620X.84B8.9361

Chacaroun, S., Borowik, A., Morrison, S. A., Baillieul, S., Flore, P., Doutreleau, S., et al. (2017). Physiological responses to two hypoxic conditioning strategies in healthy subjects. Front. Physiol. 7:675. doi: 10.3389/fphys.2016.00675

Cheng, Y. J., Chien, C. T., and Chen, C. F. (2003). Oxidative stress in bilateral total knee replacement, under ischaemic tourniquet. J. Bone Joint Surg. Br. 85, 679-682. doi: 10.1302/0301-620X.85B5.13539

Chomczynski, P., and Sacchi, N. (1987). Single-step method of RNA isolation by acid guanidinium thiocyanate-phenol-chloroform extraction. Anal. Biochem. 162, 156-159. doi: 10.1016/0003-2697(87)90021-2

Cohen, J. (1992). A power primer. Psychol. Bull. 112, 155-159. doi: 10.1037/0033-2909.112.1.155

Costa, R. J. S., Crockford, M. J., Moore, J. P., and Walsh, N. P. (2012). Heat acclimation responses of an ultra-endurance running group preparing for hot desert-based competition. Eur. J. Sport Sci. 14, 1-11. doi: 10.1080/17461391.2012.660506

Cruz, R. S., de, O., De Aguiar, R. A., Turnes, T., Pereira, K. L., and Caputo, F. (2015). Effects of ischemic preconditioning on maximal constant load cycling performance. J. Appl. Physiol. 119, 961-967. doi: 10.1152/japplphysiol.00498.2015

Dakin, H., Gray, A., Fitzpatrick, R., Maclennan, G., Murray, D., and KAT Trial Group. (2012). Rationing of total knee replacement: a costeffectiveness analysis on a large trial data set. BMJ Open 2:e000332. doi: 10.1136/bmjopen-2011-000332

Debevec, T., Millet, G. P., and Pialoux, V. (2017). Hypoxia-induced oxidative stress modulation with physical activity. Front. Physiol. 8:84. doi: 10.3389/fphys.2017.00084

de Groot, P. C. E., Thijssen, D. H. J., Sanchez, M., Ellenkamp, R., and Hopman, M. T. E. (2010). Ischemic preconditioning improves maximal performance in humans. Eur. J. Appl. Physiol. 108, 141-146. doi: 10.1007/s00421-009-1195-2

Edgerton, V. R., Smith, J. L., and Simpson, D. R. (1975). Muscle fibre type populations of human leg muscles. Histochem. J. 7, 259-266. doi: $10.1007 / \mathrm{BF} 01003594$

Estebe, J.-P., Davies, J. M., and Richebe, P. (2011). The pneumatic tourniquet: mechanical, ischaemia-reperfusion and systemic effects. Eur. J. Anaesthesiol. 28, 404-411. doi: 10.1097/EJA.0b013e328346d5a9

Fatouros, I. G., Jamurtas, A. Z., Villiotou, V., Pouliopoulou, S., Fotinakis, P., Taxildaris, K., et al. (2004). Oxidative stress responses in older men during endurance training and detraining. Med. Sci. Sports Exerc. 36, 2065-2072. doi: 10.1249/01.MSS.0000147632.17450.FF

Faul, F., Erdfelder, E., Buchner, A., and Lang, A.-G. G. (2009). Statistical power analyses using $\mathrm{G}^{*}$ Power 3.1: tests for correlation and regression analyses. Behav. Res. Methods 41, 1149-1160. doi: 10.3758/BRM.41.4.1149

Febbraio, M. A., and Koukoulas, I. (2000). HSP72 gene expression progressively increases in human skeletal muscle during prolonged, exhaustive exercise. $J$. Appl. Physiol. 89, 1055-1060. Available online at: http://jap.physiology.org/ content/89/3/1055.full.pdf + html

Febbraio, M. A., Steensberg, A., Walsh, R., Koukoulas, I., van Hall, G., Saltin, B., et al. (2002). Reduced glycogen availability is associated with an elevation in HSP72 in contracting human skeletal muscle. J. Physiol. 538, 911-917. doi: 10.1113/jphysiol.2001.013145

Fehrenbach, E., Niess, A. M., Schlotz, E., Passek, F., Dickhuth, H.-H., and Northoff, H. (2000a). Transcriptional and translational regulation of heat shock proteins in leukocytes of endurance runners. J. Appl. Physiol. 89, 704-710. Available online at: http://jap.physiology.org/content/89/2/704.long

Fehrenbach, E., Niess, A. M., Veith, R., Dickhuth, H. H., and Northoff, H. (2001). Changes of HSP72-expression in leukocytes are associated with adaptation to exercise under conditions of high environmental temperature. J. Leukoc. Biol. 69, 747-754. Available online at: http://www.jleukbio.org/content/69/5/ 747.abstract

Fehrenbach, E., Niess, A., Passek, F., Sorichter, S., Schwirtz, A., Berg, A., et al. (2003a). Influence of different types of exercise on the expression of haem oxygenase-1 in leukocytes. J. Sports Sci. 21, 383-389. doi: $10.1080 / 0264041031000071164$

Fehrenbach, E., and Northoff, H. (2001). Free radicals, exercise, apoptosis, and heat shock proteins. / Radicaux libres, exercice, apoptose et proteines du choc thermique. Exerc. Immunol. Rev. 7, 66-89.

Fehrenbach, E., Passek, F., Niess, A. M., Pohla, H., Weinstock, C., Dickhuth, H. H., et al. (2000b). HSP expression in human leukocytes is modulated by endurance exercise. L'expression des proteines HSP dans les leucocytes humains est modulee par un effort d'endurance. Med. Sci. Sport. Exerc. 32, 592-600. doi: 10.1097/00005768-200003000-00007

Fehrenbach, E., Veith, R., Schmid, M., Dickhuth, H.-H., Northoff, H., and Niess, A. M. (2003b). Inverse response of leukocyte heat shock proteins and DNA damage to exercise and heat. Free Radic. Res. 37, 975-982. doi: 10.1080/10715760310001595748

Feldman, A. L., Costouros, N. G., Wang, E., Qian, M., Marincola, F. M., Alexander, H. R., et al. (2002). Advantages of mRNA amplification for microarray analysis. Biotechniques 33, 906-914. Available online at: http://www.biotechniques.com/ BiotechniquesJournal/2002/October/Advantages- of-mRNA-Amplificationfor-Microarray-Analysis/biotechniques-39915.html

Field, A. (2013). Discovering Statistics using IBM SPSS Statistics. London: Sage.

Fisher-Wellman, K., and Bloomer, R. J. (2009). Acute exercise and oxidative stress: a 30 year history. Dyn. Med. 8:1. doi: 10.1186/1476-5918-8-1

Fitzgibbons, P. G., DiGiovanni, C., Hares, S., and Akelman, E. (2012). Safe tourniquet use: a review of the evidence. J. Am. Acad. Orthop. Surg. 20, 310-319. doi: 10.5435/00124635-201205000-00007

Foster, J., Mauger, A., Thomasson, K., White, S., and Taylor, L. (2016). Effect of acetaminophen ingestion on thermoregulation of normothermic, non-febrile humans. Front. Pharmacol. 7:54. doi: 10.3389/fphar.2016.00054

Gibson, O. R., Mee, J. A., Taylor, L., Tuttle, J. A., Watt, P. W., Maxwell, N. S., et al. (2015a). Isothermic and fixed-intensity heat acclimation methods elicit equal increases in Hsp72 mRNA. Scand. J. Med. Sci. Sports 25, 259-268. doi: $10.1111 /$ sms. 12430

Gibson, O. R., Taylor, L., Watt, P. W., and Maxwell, N. S. (2017). Cross adaptation - heat and cold adaptation to improve physiological and cellular responses to hypoxia. Sports Med. doi: 10.1007/s40279-017-0717-z. [Epub ahead of print].

Gibson, O. R., Turner, G., Tuttle, J. A., Taylor, L., Watt, P. W., and Maxwell, N. S. (2015b). Heat acclimation attenuates physiological strain and the HSP72, but not HSP90 $\alpha$, mRNA response to acute normobaric hypoxia. J. Appl. Physiol. 119, 889-899. doi: 10.1152/japplphysiol.00332.2015

Gibson, O. R., Tuttle, J. A., Watt, P. W., Maxwell, N. S., and Taylor, L. (2016). Hsp72 and Hsp90 $\alpha$ mRNA transcription is characterised by large, sustained changes in core temperature during heat acclimation. Cell Stress Chaperones 21, 1021-1035. doi: 10.1007/s12192-016-0726-0 
Gozzelino, R., Jeney, V., and Soares, M. P. (2010). Mechanisms of cell protection by heme oxygenase-1. Annu. Rev. Pharmacol. Toxicol. 50, 323-354. doi: 10.1146/annurev.pharmtox.010909.105600

Grace, P. A. (1994). Ischaemia-reperfusion injury. Br. J. Surg. 81, 637-647. doi: 10.1002/bjs.1800810504

Greif, R., Akça, O., Horn, E.-P., Kurz, A., and Sessler, D. I. (2000). Supplemental perioperative oxygen to reduce the incidence of surgical-wound infection. $N$. Engl. J. Med. 342, 161-167. doi: 10.1056/NEJM200001203420303

Halliwell, B., and Chirico, S. (1993). Lipid peroxidation: its mechanism, measurement, and significance. Am. J. Clin. Nutr. 57, 715S-724S. discussion: 724S-725S.

Hawkins, C. L., and Davies, M. J. (2001). Generation and propagation of radical reactions on proteins. Biochim. Biophys. Acta 1504, 196-219. doi: 10.1016/S0005-2728(00)00252-8

Henstridge, D. C., Whitham, M., and Febbraio, M. A. (2014). Chaperoning to the metabolic party: the emerging therapeutic role of heat-shock proteins in obesity and type 2 diabetes. Mol. Metab. 3, 781-793. doi: 10.1016/j.molmet.2014.08.003

Hepponstall, M., Ignjatovic, V., Binos, S., Monagle, P., Jones, B., Cheung, M. H. H., et al. (2012). Remote Ischemic Preconditioning (RIPC) modifies plasma proteome in humans. PLoS ONE 7:e48284. doi: 10.1371/journal.pone.0048284

Hillman, A. R., Vince, R. V., Taylor, L., McNaughton, L., Mitchell, N., and Siegler, J. (2011). Exercise-induced dehydration with and without environmental heat stress results in increased oxidative stress. Appl. Physiol. Nutr. Metab. 36, 698-706. doi: 10.1139/h11-080

Horowitz, M., Maloyan, A., and Shlaier, J. (1997). HSP70 kDa dynamics in animals undergoing heat stress superimposed on heat acclimation. Thermoregulation $813,617-619$.

James, C. A., Willmott, A. G. B., Richardson, A. J., Watt, P. W., and Maxwell, N. S. (2016). Ischaemic preconditioning does not alter the determinants of endurance running performance in the heat. Eur. J. Appl. Physiol. 116, 1735-1745. doi: 10.1007/s00421-016-3430-y

Kalmar, B., and Greensmith, L. (2009). Induction of heat shock proteins for protection against oxidative stress. Adv. Drug Deliv. Rev. 61, 310-318. doi: 10.1016/j.addr.2009.02.003

Karg, E., Nemeth, I., Virag, G., Meszaros, T., Boda, D., and Pinter, S. (1997). Oxidative stress induced by bloodless limb surgery on humans. Eur. J. Clin. Invest. 27, 984-991. doi: 10.1046/j.1365-2362.1997.2130768.x

Khassaf, M., Child, R. B., McArdle, A., Brodie, D. A., Esanu, C., and Jackson, M. J. (2001). Time course of responses of human skeletal muscle to oxidative stress induced by nondamaging exercise. J. Appl. Physiol. 90, 1031-1035. Available online at: http://jap.physiology.org/content/90/3/1031.long

Kido, K., Suga, T., Tanaka, D., Honjo, T., Homma, T., Fujita, S., et al. (2015). Ischemic preconditioning accelerates muscle deoxygenation dynamics and enhances exercise endurance during the work-to-work test. Physiol. Rep. 3:e12395. doi: 10.14814/phy2.12395

Koca, K., Yurttas, Y., Cayci, T., Bilgic, S., Kaldirim, U., Durusu, M., et al. (2011). The role of preconditioning and $\mathrm{N}$-acetylcysteine on oxidative stress resulting from tourniquet-induced ischemia-reperfusion in arthroscopic knee surgery. J. Trauma Inj. Infect. Crit. Care 70, 717-723. doi: 10.1097/TA.0b013e3181f30fb0

Kocman, E. A., Ozatik, O., Sahin, A., Guney, T., Kose, A. A., Dag, I., et al. (2015). Effects of ischemic preconditioning protocols on skeletal muscle ischemiareperfusion injury. J. Surg. Res. 193, 942-952. doi: 10.1016/j.jss.2014.09.032

Konstantinov, I. E., Arab, S., Kharbanda, R. K., Li, J., Cheung, M. M. H., Cherepanov, V., et al. (2004). The remote ischemic preconditioning stimulus modifies inflammatory gene expression in humans. Physiol. Genomics 19, 143-150. doi: 10.1152/physiolgenomics.00046.2004

Kregel, K. C. (2002). Heat shock proteins: modifying factors in physiological stress responses and acquired thermotolerance. J. Appl. Physiol. 92, 2177-2186. doi: 10.1152/japplphysiol.01267.2001

Kuennen, M., Gillum, T., Dokladny, K., Bedrick, E., Schneider, S., and Moseley, P. (2011). Thermotolerance and heat acclimation may share a common mechanism in humans. Am. J. Physiol. Regul. Integr. Comp. Physiol. 301, R524-R533. doi: 10.1152/ajpregu.00039.2011

Landry, J., Bernier, D., Chrétien, P., Nicole, L. M., Tanguay, R. M., and Marceau, N. (1982). Synthesis and degradation of heat shock proteins during development and decay of thermotolerance. Cancer Res. 42, 2457-2461.

Lee, B. J., Emery-Sinclair, E. L., Mackenzie, R. W., Hussain, A., Taylor, L., James, R. S., et al. (2014). The impact of submaximal exercise during heat and/or hypoxia on the cardiovascular and monocyte HSP72 responses to subsequent (post 24 h) exercise in hypoxia. Extrem. Physiol. Med. 3:15. doi: 10.1186/2046-7648-3-15 Lee, B. J., Miller, A., James, R. S., and Thake, C. D. (2016). Cross acclimation between heat and hypoxia: heat acclimation improves cellular tolerance and exercise performance in acute normobaric hypoxia. Front. Physiol. 7:78. doi: 10.3389/fphys.2016.00078

Levine, B. D., Zuckerman, J. H., and deFilippi, C. R. (1997). Effect of high-altitude exposure in the elderly. Circulation 96, 1224-1232. doi: 10.1161/01.CIR.96.4.1224

Liu, Y., Lormes, W., Wang, L., Reissnecker, S., and Steinacker, J. M. (2004). Different skeletal muscle HSP70 responses to high-intensity strength training and low-intensity endurance training. Eur. J. Appl. Physiol. 91, 330-335. doi: 10.1007/s00421-003-0976-2

Liu, Y., Mayr, S., Opitz-Gress, A., Zeller, C., Lormes, W., Baur, S., et al. (1999). Human skeletal muscle HSP70 response to training in highly trained rowers. J. Appl. Physiol. 86, 101-104.

Logan-Sprenger, H. M., Heigenhauser, G. J. F., Jones, G. L., and Spriet, L. L. (2015). The effect of dehydration on muscle metabolism and time trial performance during prolonged cycling in males. Physiol. Rep. 3:e12483. doi: $10.14814 /$ phy2.12483

Loukogeorgakis, S. P., Panagiotidou, A. T., Broadhead, M. W., Donald, A., Deanfield, J. E., and MacAllister, R. J. (2005). Remote ischemic preconditioning provides early and late protection against endothelial ischemia-reperfusion injury in humans. J. Am. Coll. Cardiol. 46, 450-456. doi: 10.1016/j.jacc.2005.04.044

Lyamina, N. P., Lyamina, S. V., Senchiknin, V. N., Mallet, R. T., Downey, H. F., and Manukhina, E. B. (2011). Normobaric hypoxia conditioning reduces blood pressure and normalizes nitric oxide synthesis in patients with arterial hypertension. J. Hypertens. 29, 2265-2272. doi: 10.1097/HJH.0b013e32834b5846

Maloyan, A., Palmon, A., and Horowitz, M. (1999). Heat acclimation increases the basal HSP72 level and alters its production dynamics during heat stress. Am. J. Physiol. 276, R1506-R1515.

Marber, M. S., Latchman, D. S., Walker, J. M., and Yellon, D. M. (1993). Cardiac stress protein elevation 24 hours after brief ischemia or heat stress is associated with resistance to myocardial infarction. Circulation 88, 1264-1272. doi: 10.1161/01.CIR.88.3.1264

Marber, M. S., Mestril, R., Chi, S. H., Sayen, M. R., Yellon, D. M., and Dillmann, W. H. (1995). Overexpression of the rat inducuble 70KD heat-stress protein in a transgenic mouse increases the resistance of the heart to ischemic-injury. J. Clin. Invest. 95, 1446-1456. doi: 10.1172/JCI117815

Marshall, H., Chrismas, B. C., Suckling, C. A., Roberts, J. D., Foster, J., and Taylor, L. (2017). Chronic probiotic supplementation with or without glutamine does not influence the eHsp72 response to a multi-day ultra-endurance exercise event. Appl. Physiol. Nutr. Metab. 1, 1-8. doi: 10.1139/apnm-2017-0131

Mateika, J. H., El-Chami, M., Shaheen, D., and Ivers, B. (2014). Intermittent hypoxia: A low risk research tool with therapeutic value in humans. J. Appl. Physiol. 118, 520-532. doi: 10.1152/japplphysiol.00564.2014

Mee, J. A., Gibson, O. R., Tuttle, J. A., Taylor, L., Watt, P. W., Doust, J., et al. (2016). Leukocyte Hsp72 mRNA transcription does not differ between males and females during heat acclimation. Temperature 3, 549-556. doi: 10.1080/23328940.2016.1214336

Mekjavic, I. B., Amon, M., Kölegård, R., and Kounalakis, S. N. (2016). The effect of normobaric hypoxic confinement on metabolism, gut hormones, and body composition. Front Physiol. 7:202. doi: 10.3389/fphys.2016. 00202

Memtsoudis, S. G., Stundner, O., Yoo, D., Gonzalez Della Valle, A., Boettner, F., Bombardieri, A. M., et al. (2014). Does limb preconditioning reduce pain after total knee arthroplasty? A randomized, double-blind study. Clin. Orthop. Relat. Res. 472, 1467-1474. doi: 10.1007/s11999-013-3106-4

Memtsoudis, S. G., Valle, A. G., Jules-Elysse, K., Poultsides, L., Reid, S., Starcher, B., et al. (2010). Perioperative inflammatory response in total knee arthroplasty patients: impact of limb preconditioning. Reg. Anesth. Pain Med. 35, 412-416. doi: 10.1097/AAP.0b013e3181e82e8e

Mestre-Alfaro, A., Ferrer, M. D., Banquells, M., Riera, J., Drobnic, F., Sureda, A., et al. (2012). Body temperature modulates the antioxidant and acute immune responses to exercise. Free Radic. Res. 46, 799-808. doi: $10.3109 / 10715762.2012 .680193$ 
Millet, G., Roels, B., Schmitt, L., Woorons, X., and Richalet, J. P. (2010). Combining hypoxic methods for peak performance. Sports Med. 40, 1-25. doi: 10.2165/11317920-000000000-00000

Miyazaki, H., Oh-ishi, S., Ookawara, T., Kizaki, T., Toshinai, K., Ha, S., et al. (2001). Strenuous endurance training in humans reduces oxidative stress following exhausting exercise. Eur. J. Appl. Physiol. 84, 1-6. doi: 10.1007/s004210000342

Morton, J. P., Holloway, K., Woods, P., Cable, N. T., Burniston, J., Evans, L., et al. (2009a). Exercise training-induced gender-specific heat shock protein adaptations in human skeletal muscle. Muscle Nerve 39, 230-233. doi: $10.1002 /$ mus. 21182

Morton, J. P., Kayani, A. C., McArdle, A., and Drust, B. (2009b). The exerciseinduced stress response of skeletal muscle, with specific emphasis on humans. Sport. Med. 39, 643-662. doi: 10.2165/00007256-200939080-00003

Morton, J. P., MacLaren, D. P. M., Cable, N. T., Bongers, T., Griffiths, R. D., Campbell, I. T., et al. (2006). Time course and differential responses of the major heat shock protein families in human skeletal muscle following acute nondamaging treadmill exercise. J. Appl. Physiol. 101, 176-182. doi: 10.1152/japplphysiol.00046.2006

Morton, J. P., Maclaren, D. P. M., Cable, N. T., Campbell, I. T., Evans, L., Bongers, T., et al. (2007). Elevated core and muscle temperature to levels comparable to exercise do not increase heat shock protein content of skeletal muscle of physically active men. Acta Physiol. 190, 319-327. doi: 10.1111/j.1748-1716.2007.01711.x

Morton, J. P., Maclaren, D. P. M., Cable, N. T., Campbell, I. T., Evans, L., Kayani, A. C., et al. (2008). Trained men display increased basal heat shock protein content of skeletal muscle. Med. Sci. Sports Exerc. 40, 1255-1262. doi: 10.1249/MSS.0b013e31816a7171

Murry, C. E., Jennings, R. B., and Reimer, K. A. (1986). Preconditioning with ischemia: a delay of lethal cell injury in ischemic myocardium. Circulation 74, 1124-1136. doi: 10.1161/01.CIR.74.5.1124

Niess, A. M., Fehrenbach, E., Schlotz, E., Sommer, M., Angres, C., Tschositsch, K., et al. (2002). Effects of RRR-alpha-tocopherol on leukocyte expression of HSP72 in response to exhaustive treadmill exercise. Int. J. Sports Med. 23, 445-452. doi: $10.1055 / \mathrm{s}-2002-33741$

Noble, E. G., Milne, K. J., and Melling, C. W. J. (2008). Heat shock proteins and exercise: a primer. Appl. Physiol. Nutr. Metab. 33, 1050-1065. doi: 10.1139/H08-069

Oksala, N. K. J., Ekmekçi, F. G., Ozsoy, E., Kirankaya, S., Kokkola, T., Emecen, G., et al. (2014). Natural thermal adaptation increases heat shock protein levels and decreases oxidative stress. Redox Biol. 3, 25-28. doi: 10.1016/j.redox.2014.10.003

Orban, J.-C., Levraut, J., Gindre, S., Deroche, D., Schlatterer, B., Ichai, C., et al. (2006). Effects of acetylcysteine and ischaemic preconditioning on muscular function and postoperative pain after orthopaedic surgery using a pneumatic tourniquet. Eur. J. Anaesthesiol. 23, 1025-1030. doi: $10.1017 /$ S026502150600086X

Otani, H. (2008). Ischemic preconditioning: from molecular mechanisms to therapeutic opportunities. Antioxid. Redox Signal. 10, 207-248. doi: $10.1089 /$ ars.2007.1679

Paroo, Z., Dipchand, E. S., and Noble, E. G. (2002). Estrogen attenuates postexercise HSP70 expression in skeletal muscle. Am. J. Physiol. Cell Physiol. 282, C245-C251. doi: 10.1152/ajpcell.00336.2001

Peart, D. J., Kirk, R. J., Madden, L. A., and Vince, R., V (2015). Implications of a pre-exercise alkalosis-mediated attenuation of HSP72 on its response to a subsequent bout of exercise. Amino Acids 48, 499-504. doi: 10.1007/s00726-015-2103-1

Pingitore, A., Lima, G. P. P., Mastorci, F., Quinones, A., Iervasi, G., and Vassalle, C. (2015). Exercise and oxidative stress: potential effects of antioxidant dietary strategies in sports. Nutrition 31, 916-922. doi: 10.1016/j.nut.2015. 02.005

Powers, S. K., Duarte, J., Kavazis, A. N., and Talbert, E. E. (2010a). Reactive oxygen species are signalling molecules for skeletal muscle adaptation. Exp. Physiol. 95, 1-9. doi: 10.1113/expphysiol.2009.050526

Powers, S. K., and Jackson, M. J. (2008). Exercise-induced oxidative stress: cellular mechanisms and impact on muscle force production. Physiol. Rev. 88, 1243-1276. doi: 10.1152/physrev.00031.2007

Powers, S. K., Smuder, A. J., Kavazis, A. N., and Hudson, M. B. (2010b). Experimental guidelines for studies designed to investigate the impact of antioxidant supplementation on exercise performance. Int. J. Sport Nutr. Exerc. Metab. 20, 2-14. doi: 10.1123/ijsnem.20.1.2

Primeau, A. J., Adhihetty, P. J., and Hood, D. A. (2002). Apoptosis in heart and skeletal muscle. Can. J. Appl. Physiol. 27, 349-395. doi: 10.1139/h02-020

Puntschart, A., Vogt, M., Widmer, H. R., Hoppeler, H., and Billeter, R. (1996). Hsp70 expression in human skeletal muscle after exercise. Acta Physiol. Scand. 157, 411-417. doi: 10.1046/j.1365-201X.1996.512270000.x

Radak, Z., Chung, H. Y., Koltai, E., Taylor, A. W., and Goto, S. (2008). Exercise, oxidative stress and hormesis. Ageing Res. Rev. 7, 34-42. doi: 10.1016/j.arr.2007.04.004

Ray, P. D., Huang, B.-W., and Tsuji, Y. (2012). Reactive oxygen species (ROS) homeostasis and redox regulation in cellular signaling. Cell. Signal. 24, 981-990. doi: 10.1016/j.cellsig.2012.01.008

Sabino-Carvalho, J. L. C., Lopes, T. R., Freitas, T. O., Ferreira, T. H. N., Succi, J. E., Silva, A. C., et al. (2016). Effect of ischemic preconditioning on endurance performance does not surpass placebo. Med. Sci. Sports Exerc. 49, 24-132. doi: 10.1249/MSS.0000000000001088

Saita, Y., Yokoyama, K., Nakamura, K., and Itoman, M. (2002). Protective effect of ischaemic preconditioning against ischaemia-induced reperfusion injury of skeletal muscle: how many preconditioning cycles are appropriate? Br. J. Plast. Surg. 55, 241-245. doi: 10.1054/bjps.2002.3809

Samaja, M., and Milano, G. (2015). Editorial - hypoxia and reoxygenation: from basic science to bedside. Front. Pediatr. 3:86. doi: 10.3389/fped.2015.00086

Sandström, M. E., Madden, L. A., Taylor, L., Siegler, J. C., Lovell, R. J., Midgley, A., et al. (2009). Variation in basal heat shock protein 70 is correlated to core temperature in human subjects. Amino Acids 37, 279-284. doi: 10.1007/s00726-008-0144-4

Schmittgen, T. D., and Livak, K. J. (2008). Analyzing real-time PCR data by the comparative CT method. Nat. Protoc. 3, 1101-1108. doi: 10.1038/nprot.2008.73

Simar, D., Malatesta, D., Mas, E., Delage, M., and Caillaud, C. (2012). Effect of an 8-weeks aerobic training program in elderly on oxidative stress and HSP72 expression in leukocytes during antioxidant supplementation. J. Nutr. Health Aging 16, 155-161. doi: 10.1007/s12603-011-0106-5

Simpson, E. J., Debevec, T., Eiken, O., Mekjavic, I., and Macdonald, I. A. (2016). PlanHab: the combined and separate effects of 16 days of bed rest and normobaric hypoxic confinement on circulating lipids and indices of insulin sensitivity in healthy men. J. Appl. Physiol. 120, 947-955. doi: 10.1152/japplphysiol.00897.2015

Smith, I. D. M., Elton, R., Ballantyne, J. A., and Brenkel, I. J. (2008). Pre-operative predictors of the length of hospital stay in total knee replacement. J. Bone Joint. Surg. Br. 90, 1435-1440. doi: 10.1302/0301-620X.90B11.20687

Smith, T. O., and Hing, C. B. (2010). Is a tourniquet beneficial in total knee replacement surgery? A meta-analysis and systematic review. Knee 17, 141-147. doi: 10.1016/j.knee.2009.06.007

Soneja, A., Drews, M., and Malinski, T. (2005). Role of nitric oxide, nitroxidative and oxidative stress in wound healing. Pharmacol. Rep. 57(Suppl.), 108-119.

Taylor, L., Hillman, A., and Midgley, A. (2012). Hypoxia mediated prior induction of monocyte-expressed HSP72 and HSP32 provides protection to the disturbances to redox balance associated with human sub-maximal aerobic exercise. Amino Acids 43, 1933-1944. doi: 10.1007/s00726-012-1265-3

Taylor, L., Lee, B. J., Gibson, O. R., Midgley, A. W., Watt, P., Mauger, A., et al. (2016). Effective microorganism - X attenuates circulating superoxide dismutase following an acute bout of intermittent running in hot, humid conditions. Res. Sport. Med. 24, 130-144. doi: 10.1080/15438627.2015.1126279

Taylor, L., Midgley, A., and Chrismas, B. (2010a). The effect of acute hypoxia on heat shock protein 72 expression and oxidative stress in vivo. Eur. J. Appl. Physiol. 109, 849-855. doi: 10.1007/s00421-010-1430-x

Taylor, L., Midgley, A. W., Chrismas, B., Hilman, A. R., Madden, L. A., Vince, R. V., et al. (2011). Daily hypoxia increases basal monocyte HSP72 expression in healthy human subjects. Amino Acids 40, 393-401. doi: 10.1007/s00726-010-0644-x

Taylor, L., Midgley, A. W., Chrismas, B., Madden, L. A., Vince, R. V., and McNaughton, L. R. (2010b). Daily quadratic trend in basal monocyte expressed HSP72 in healthy human subjects. Amino Acids 38, 1483-1488. doi: 10.1007/s00726-009-0360-6

Theodorakis, N. G., Drujan, D., and De Maio, A. (1999). Thermotolerant cells show an attenuated expression of Hsp70 after heat shock. J. Biol. Chem. 274, 12081-12086. doi: 10.1074/jbc.274.17.12081 
Tomai, F., Crea, F., Chiariello, L., and Gioffrè, P. A. (1999). Ischemic preconditioning in humans. Circulation 100, 559-563. doi: 10.1161/01.CIR.100.5.559

Trappe, T. A., Standley, R. A., Liu, S. Z., Jemiolo, B., Trappe, S. W., and Harber, M. P. (2013). Local anesthetic effects on gene transcription in human skeletal muscle biopsies. Muscle Nerve 48, 591-593. doi: 10.1002/mus.23860

Turner, G., Gibson, O. R., Watt, P. W., Pringle, J. S. M., Richardson, A. J., and Maxwell, N. S. (2016). The time course of endogenous erythropoietin, IL-6, and TNF $\alpha$ in response to acute hypoxic exposures. Scand. J. Med. Sci. Sports 27, 714-723. doi: $10.1111 /$ sms. 12700

Tuttle, J. A., Castle, P. C., Metcalfe, A. J., Midgley, A. W., Taylor, L., and Lewis, M. P. (2015). Downhill running and exercise in hot environments increase leukocyte Hsp 72 (HSPA1A) and Hsp90 $\alpha$ (HSPC1) gene transcripts. J. Appl. Physiol. 118, 996-1005. doi: 10.1152/japplphysiol.00387.2014

Tuttle, J., Chrismas, D. B. C. R., Gibson, O. R., Barrington, J. H., Hughes, D. C., Castle, P. C., et al. (2017). The Hsp72 and Hsp90 $\alpha$ mRNA responses to hot downhill running are reduced following a prior bout of hot downhill running, and occur concurrently within leukocytes and the vastus lateralis. Front. Physiol. 8:473. doi: 10.3389/fphys.2017.00473

Verges, S., Chacaroun, S., Godin-Ribuot, D., and Baillieul, S. (2015). Hypoxic conditioning as a new therapeutic modality. Front. Pediatr. 3:58. doi: 10.3389 /fped.2015.00058

Vesely, M. J., Sanders, R., Green, C. J., and Motterlini, R. (1999). Fibre type specificity of haem oxygenase-1 induction in rat skeletal muscle. FEBS Lett. 458, 257-260. doi: 10.1016/S0014-5793(99)01129-1

Vincent, H. K., Vincent, K. R., Bourguignon, C., and Braith, R. W. (2005). Obesity and postexercise oxidative stress in older women. Med. Sci. Sports Exerc. 37, 213-219. doi: 10.1249/01.MSS.0000152705.77073.B3

Vinetti, G., Mozzini, C., Desenzani, P., Boni, E., Bulla, L., Lorenzetti, I., et al. (2015). Supervised exercise training reduces oxidative stress and cardiometabolic risk in adults with type 2 diabetes: a randomized controlled trial. Sci. Rep. 5:9238. doi: $10.1038 /$ srep09238

Waikakul, S., Unnanantana, A., and Vanadurongwan, V. (1999). The role of allopurinol in digital replantation. J. Hand Surg. J. Br. Soc. Surg. Hand 24, 325-327. doi: 10.1054/JHSB.1998.0215
Whitham, M., Walker, G. J., and Bishop, N. C. (2006). Effect of caffeine supplementation on the extracellular heat shock protein 72 response to exercise. J. Appl. Physiol. 101, 1222-1227. doi: 10.1152/japplphysiol.00409.2006

Winter, J., Klumpe, I., Heger, J., Rauch, U., Schultheiss, H.-P., Landmesser, U., et al. (2016). Adenine nucleotide translocase 1 overexpression protects cardiomyocytes against hypoxia via increased ERK1/2 and AKT activation. Cell. Signal. 28, 152-159. doi: 10.1016/j.cellsig.2015.11.002

Wischmeyer, P. E., Kahana, M., Wolfson, R., Ren, H., Musch, M. M., and Chang, E. B. (2001). Glutamine induces heat shock protein and protects against endotoxin shock in the rat. J. Appl. Physiol. 90, 2403-2410. Available online at: http://jap. physiology.org/content/90/6/2403.long

Worland, R. L., Arredondo, J., Angles, F., Lopez-Jimenez, F., and Jessup, D. E. (1997). Thigh pain following tourniquet application in simultaneous bilateral total knee replacement arthroplasty. J. Arthroplasty 12, 848-852. doi: 10.1016/S0883-5403(97)90153-4

Wu, D., and Cederbaum, A. I. (2003). Alcohol, oxidative stress, and free radical damage. Alcohol Res. Health 27, 277-284.

Zuhl, M., Dokladny, K., Mermier, C., Schneider, S., Salgado, R., and Moseley, P. (2015). The effects of acute oral glutamine supplementation on exerciseinduced gastrointestinal permeability and heat shock protein expression in peripheral blood mononuclear cells. Cell Stress Chaperones 20, 85-93. doi: 10.1007/s12192-014-0528-1

Conflict of Interest Statement: The authors declare that the research was conducted in the absence of any commercial or financial relationships that could be construed as a potential conflict of interest.

Copyright (c) 2017 Barrington, Chrismas, Gibson, Tuttle, Pegrum, Govilkar, Kabir Giannakakis, Rayan, Okasheh, Sanaullah, Ng Man Sun, Pearce and Taylor. This is an open-access article distributed under the terms of the Creative Commons Attribution License (CC BY). The use, distribution or reproduction in other forums is permitted, provided the original author(s) or licensor are credited and that the original publication in this journal is cited, in accordance with accepted academic practice. No use, distribution or reproduction is permitted which does not comply with these terms. 